\title{
PLATAFORMA TECNOLÓGICA DE APOIO À EDUCAÇÃO PROFISSIONAL
}

\author{
Eduardo Gonçalves d'Avila Filho ${ }^{1}$
}

Luciano Blauth ${ }^{2}$

Paulo Alberto Macedo Vieira Violada ${ }^{3}$

\section{RESUMO}

O mundo vem passando por mudanças cada vez mais profundas e significativas, estando mais diversificado e interconectado. Vive-se uma era das conexões, de uma sociedade em rede, o que é proporcionado principalmente pela massificação do uso das tecnologias de informação e comunicação. Isto transforma também o mundo do trabalho, exigindo um novo perfil do trabalhador, cada vez menos um repetidor de tarefas e cada vez mais um solucionador de problemas. Isto, aliado ao fato de se presenciar uma nova geração que já nasceu em um mundo digital, exige mudanças no universo educacional, especialmente na educação profissional, tanto no âmbito pedagógico, quanto em um escopo tecnológico. Este artigo apresenta uma proposta de plataforma tecnológica de suporte aos processos de ensino e aprendizagem, com um foco na educação profissional, alinhada às necessidades de formação de um novo profissional, adequado às demandas do mundo atual e futuro. Tal proposta apresenta oito principais elementos: dispositivos de projeção e interação, ambiente virtual de aprendizagem (AVA), banco de recursos didáticos, portfólio digital, ferramentas de comunicação e colaboração, simulações, jogos e acesso remoto a laboratórios. Sua aplicação, sustentada por uma proposta pedagógica adequada, resulta em uma educação profissional mais significativa e alinhada às necessidades do mundo do trabalho atual e futuro.

Palavras-chave: Educação profissional. Tecnologias da Informação e Comunicação. Tecnologia Educacional.

\footnotetext{
${ }^{1}$ Mestre. E-mail: eduardo@sc.senai.br

2Especialista. E-mail: lucianob@sc.senai.br

${ }^{3}$ Especialista. E-mail: pauloav@sc.senai.br
} 


\section{INTRODUÇÃO}

O mundo passa constantemente por transformações. Nas últimas décadas do século 20, a chegada e disseminação das tecnologias digitais causaram uma enorme mudança no mundo. Alterações na forma como nos relacionamos, comunicamos, divertimos e trabalhamos são evidentes. Os jovens que nasceram a partir do fim do século passado e estão entrando no mercado de trabalho, já nasceram em um mundo digital, conectado.

Estas mudanças, porém, não são tão fortes no mundo educacional, o qual prepara os estudantes não para o futuro, mas para uma realidade que não existe mais. É preciso quebrar este paradigma, modificando tanto o que se ensina quanto como se ensina, adequando os processos pedagógicos e a estrutura tecnológica para atender às demandas deste novo mundo.

Neste artigo objetiva-se identificar as características profissionais exigidas pelo mundo, especialmente o do trabalho, e as necessidades de adequação do modelo educacional, propondo uma estrutura tecnológica de suporte aos processos de ensino e aprendizagem, em especial na educação profissional.

\section{O IMPACTO DAS TECNOLOGIAS DA INFORMAÇÃO E COMUNICAÇÃO}

Ao longo da história o mundo passou por mudanças, as quais acontecem cada vez com maior frequência e profundidade. Neste sentido, Perez (2002, tradução nossa) destaca cinco revoluções tecnológicas que aconteceram desde o século XVIII que modificaram não só os modelos econômicos, empresariais e de organização da produção, mas também as estruturas geopolíticas e sociais, cujos respectivos momentos que marcaram seu início foram:

1) 1771 - A "Revolução Industrial": moinho Arkwright é aberto em Cromford, Inglaterra

2) 1829 - Era do Vapor e das Ferrovias: teste da locomotiva a vapor Rocket para a ferrovia Liverpool - Manchester

3) 1875 - Era do Aço, da Eletricidade e da Engenharia Pesada: a siderúrgica Carnegie Bessemer é aberta em Pittsburgh, Estados Unidos

4) 1908 - Era do Petróleo, do Automóvel e da Produção em Massa: primeiro Ford modelo T é produzido na fábrica da Ford em Detroit, Estados Unidos

5) 1971 - Era da Informação e das Telecomunicações: o microprocessador da Intel é anunciado em Santa Clara, Estados Unidos. 
A partir deste último marco, o desenvolvimento das telecomunicações, o surgimento das redes de comunicação - em especial a internet - e a massificação dos computadores e demais instrumentos digitais têm mudado o mundo.

As informações estão cada vez intensas, distribuídas e acessíveis; as estruturas rígidas e hierárquicas dão lugar a estruturas em rede; o conhecimento passa a ser valorizado como capital; o intangível passa a ter valor; heterogeneidade, diversidade e adaptabilidade são características cada vez mais fortes na sociedade e nos negócios; há uma segmentação de mercados e a proliferação de nichos, porém combinadas com uma dimensão em escala; o global e o local interagem fortemente; a cooperação é fator cada vez mais presente e a comunicação com qualquer parte do globo é instantânea, permitindo contatos e ações imediatas (PEREZ, 2002, tradução nossa).

Outro aspecto que merece destaque, o qual acompanha estas evoluções tecnológicas, é a redução das barreiras impostas pelas distâncias físicas e geográficas, proporcionada inicialmente pelos meios de transporte e, mais recentemente, pelas tecnologias da informação e comunicação (TIC), que podem ser definidas como "um variado conjunto de ferramentas e recursos tecnológicos usados para comunicação e para criar, disseminar, armazenar e gerenciar informações." (BLURTON, 1999, p.1, tradução nossa)

Estas tecnologias, as quais incluem computadores, a internet, tecnologias de radiodifusão (rádio, TV) e telefonia, têm oferecido facilidades para a realização da comunicação que independem de distâncias geográficas e permitem uma ampla disseminação de informações (MULLER, 1994;PEREZ, 2002, tradução nossa; REICH, 2002; TINIO, 2003, tradução nossa).

No bazar mundial emergente, a distância física está em via de deixar de ser um empecilho. A economia está se afastando do material em prol dos serviços virtuais que podem ser transmitidos a qualquer parte do mundo a um custo ínfimo. Cada vez mais, o valor de mercado de quase tudo é transmitido, à velocidade da luz, por satélite ou fibra ótica. (REICH, 2002, p. 21)

Termos como mundo conectado, sociedade do conhecimento, sociedade da informação, sociedade em rede, era digital, era das conexões etc. têm sido utilizados para denominar este momento em que vivemos.

\subsection{0 mundo do trabalho exige novas competências}

Todas estas mudanças, porém, não se restringem apenas ao campo tecnológico. 0 mundo do trabalho também passou por diversas transformações tanto na organização do trabalho quanto no papel exercido pelos trabalhadores, as quais vêm ocorrendo desde a época dos artesãos, passando pelas propostas clássicas de administração de Taylor, Fayol e Mayo, pelo auge do modelo japonês, chegando até a realidade atual. (ROTTA, 2001) 
Em praticamente todos os setores da economia, atividades que demandam dos trabalhadores ações meramente de rotina, repetitivas, são cada vez mais realizadas por computadores. Desta forma, é crescente a necessidade de que estes trabalhadores sejam capazes de encontrar e analisar informações das mais diversas fontes, usando-as para tomar decisões e criar novas ideias. (ANDERSON, 2010, tradução nossa; LEVY e MURNANE, 2004, tradução nossa; SILVA, 2009,tradução nossa).

Este perfil necessário para o trabalhador de hoje é composto pelo que vem comumente sendo chamado de "habilidades do século 21". Diversas categorizações têm sido utilizadas para definir estas habilidades por diferentes autores. Em sua maioria, porém, estes apontam para a necessidade do desenvolvimento de estudantes e trabalhadores que tenham capacidade de raciocínio crítico, que possam efetivamente pensar sobre aspectos complexos, sejam solucionadores de problemas, trabalhem de maneira colaborativa e sejam tomadores de decisão, usando-se de estratégias apropriadas em contextos apropriados e beneficiando-se dos recursos tecnológicos existentes. (ANDERMAN, 2011, tradução nossa; SILVA, 2009, tradução nossa)

Vale ressaltar que apesar deste rótulo temporal, raciocínio crítico, analítico e criativo não são habilidades específicas ou exclusivas do século 21 , uma vez que argumentos semelhantes já foram apresentados por filósofos e educadores através dos séculos. Porém, estas demandas acentuaram-se nas duas últimas décadas, por conta das mudanças na natureza da economia e do trabalho (SILVA, 2009, tradução nossa).

Neste contexto faz-se destaque ao papel das escolas que, segundo Mantoan (2002, p. 18), "são incubadoras do novo e têm papel inestimável e imprescindível na formação dos cidadãos deste milênio que desponta".

Porém é necessária uma adequação do modelo educacional para o atendimento a tais requisitos apresentados pelo mundo atual e futuro, preparando de maneira mais apropriada os estudantes e trabalhadores para este novo paradigma socioeconômico. Verifica-se que, em geral, os modelos adotados pelos sistemas educacionais não são mais adequados aos padrões desta realidade atual, havendo um descompasso entre as características do mundo e as da escola, demandando novos modos de pensar e fazer a educação. (MELO et al., 2005).

Um alinhamento às necessidades do mundo real é preciso, mudando-se o paradigma essencialmente conteudista para um foco na aplicação do que se ensina e se aprende, ou seja, dando ênfase ao que o estudante pode fazer com o conhecimento, em vez de simplesmente focar em quais conhecimentos o estudante adquire. Esta, segundo Silva (2009, tradução nossa) é a essência das habilidades do século 21.

Estas mudanças são necessárias não somente pela exigência do mundo do trabalho, mas também pela mudança no perfil dos estudantes, que mudou não de maneira incremental, mas de maneira radical em relação às gerações anteriores, a partir da chegada e rápida disseminação das tecnologias digitais na última década do século 20 (PRENSKY, 2001, tradução nossa; PEREZ, 2002, tradução nossa). 
Esta é a primeira geração que já nasceu e cresceu no convívio com estas novas tecnologias, denominada de "nativos digitais", "geração millennials", "geração da internet", "iGeração" etc., os quais têm como língua nativa a linguagem digital dos computadores, vídeo games e da internet, com estrondosas habilidades conectivas. Em contraponto, os que chegaram ao mundo antes desta revolução tecnológica, porém vivem nele, são os "imigrantes digitais". Estes podem até falar esta nova língua, porém a falam com um "sotaque" de um tempo passado em que o mundo era diferente, de uma era pré-digital (LIPKIN e PERRYMORE, 2010, tradução nossa; PRENSKY, 2001, tradução nossa; TAPSCOTT, 2008, tradução nossa).

Com isto, surge o primeiro conflito no escopo educacional. Os professores de hoje, em sua maioria, fazem parte desta geração anterior, dos imigrantes digitais, que falam uma linguagem desatualizada e que têm dificuldades de ensinar a uma população que fala uma linguagem completamente nova. (MELO et al., 2005, tradução nossa; PRENSKY, 2001, tradução nossa),

Há necessidade de mudar este contexto, de aproximar os docentes e o mundo da educação deste mundo digital, aproveitando-se dos benefícios da tecnologia para alavancar melhores resultados educacionais, formando cidadãos mais preparados para os desafios do mundo atual e futuro. Segundo Mark Prensky:

\footnotetext{
Os docentes de hoje devem aprender a se comunicarem na linguagem e estilo de seus estudantes. Isto não significa mudar o sentido do que é importante, ou das boas habilidades de raciocínio. Mas isto significa ir mais rápido, menos passo a passo, mais em paralelo, com mais acessos randômicos, entre outras coisas. (PRENSKY, 2001, p. 4, tradução nossa)
}

Com isso, os papéis da escola e do docente modificam-se. Segundo Melo et al. (2005) e Tinio (2003, tradução nossa), o acesso crescente e cada vez mais fácil às informações tem tirado das escolas o status de lugar privilegiado para a aquisição ou construção, de maneira mais sistematizada, de conhecimento. Ainda neste contexto, o mesmo acontece com o docente, que deixa de ser um mero replicador de conteúdos, intensificando seu papel de mediador do processo de aprendizagem. Mais importante que simplesmente reproduzir informações é desenvolver nos estudantes as capacidades de analisá-las, avaliá-las criticamente, utilizá-las de maneira correta e criativa, com a finalidade de resolver os problemas apresentados.

De maneira complementar, Melo et al. (2005) ressaltam que as tecnologias da informação e comunicação permitem a multiplicação das interações com diferentes pessoas, independente de sua localização geográfica, o que permite às pessoas desenvolverem outros mecanismos perceptivos, outros modos de pensar e de aprender. Estas interações podem envolver estudantes, docentes, pesquisadores, especialistas ou quaisquer atores que contribuam para o processo educacional. Isto faz com que a distinção do ensino "presencial" e "a distância" se esvazie, uma vez que "as características de uma aprendizagem aberta a distância são semelhantes às da sociedade da informação como um todo (sociedade de rede, de velocidade, de personalização, etc.)" (LÉVY, 2000, p. 170). 
Especificamente sobre este novo papel do docente, Pierre Lévy afirma:

A partir daí, a principal função do professor não pode mais ser uma difusão dos conhecimentos, que agora é feita de forma mais eficaz por outros meios. Sua competência deve deslocar-se no sentido de incentivar a aprendizagem e o pensamento. O professor torna-se um animador da inteligência coletiva dos grupos que estãoaseu encargo. Sua atividade será centrada no acompanhamento e na gestão das aprendizagens: o incitamento à troca dos saberes, a medição relacional e simbólica, a pilotagem personalizada dos percursos de aprendizagem etc. (LÉVY, 2000, p. 170-171)

Com isto, o papel dos estudantes também muda, como afirmam Melo et al.:

O cenário atual convida para o estabelecimento de relações mais dialógicas entre os atores do processo educacional, em que os alunos, ao invés de serem mantidos na posição de receptores passivos do "falar/ditar" do professor, participariam como coautores do processo, em todas as suasfases. (MELO et al., 2005, p. 2542)

Assim, o estudante passa de um receptor passivo de informação, um reprodutor de conhecimentos e um ser solitário no processo de aprendizagem, a um participante ativo deste processo, um produtor de conhecimento, aprendendo de maneira colaborativa com outros. (ANDERSON, 2010, tradução nossa).

Para atender a estas novas demandas, uma readequação de toda a escola é necessária. Este desafio, porém, não é simples, passando por diversos aspectos, dentre os quais: uma revisão do currículo, das práticas pedagógicas e mesmo da estrutura física.

Pedro Demo (2011) evidencia os impactos nos processos gerencial-pedagógicos dentro do ambiente escolar, destacando o vazio ainda existente entre o potencial dessas novas tecnologias e a prática escolar:

Muitos estudantes embarcaram nas novas tecnologias, mas não conseguem usá-las de modo inteligente, crítico e criativo, enquanto muitos professores continuam desconectados e mesmo resistentes a elas. Nesse contexto, ressalta-se a importância da preparação adequada dos professores para que sejam capazes de pensar criticamente e de influenciar positivamente seus alunos a transformar informação em conhecimento. (DEMO, 2011, p.15)

\subsection{A Educação Profissional no contexto do mundo do trabalho}

Neste cenário destaca-se o papel da educação técnica e profissional (ou vocacional), que, segundo a UNESCO, compreende:

[...] aspectos do processo educacional envolvendo, em adição à educação geral, o estudo de tecnologias e ciências relacionadas, e na aquisição de habilidades práticas, atitudes, compreensão e conhecimento relacionados a ocupações em diversos setores da vida econômica e social. (UNESCO, 2002, p. 28, tradução nossa) 
De maneira complementar, a educação profissional é um meio de preparação para áreas profissionais e para uma efetiva participação no mundo do trabalho,além de um aspecto de aprendizado ao longo da vida e uma preparação para uma cidadania responsável. (UNESCO, 2001, tradução nossa).

Especificamente, em um escopo nacional, conforme a Lei de Diretrizes e Bases da Educação (LDB), a educação técnica e profissional abrange cursos de formação inicial e continuada ou qualificação profissional, cursos deeducação profissional técnica de nível médio, tecnológica de graduação e pós-graduação (BRASIL, 1996).

A necessidade de um alinhamento entre as demandas do mundo real e a prática educacional explicita-se fortemente na educação profissional. Para a construção de um curso ou programa, parte-se de um olhar para as demandas do mundo do trabalho, identificando-as e estruturando, inicialmente, o perfil profissional correspondente a determinada qualificação em questão, apresentando as competências profissionais exigidas para seu exercício (SENAI, 2009a).

Este perfil, por sua vez, deve ser traduzido em um desenho curricular (ou seja, o que se ensina) alinhado a estas demandas e que permita o desenvolvimento das competências estabelecidas no perfil, com "o objetivo de formar o trabalhador-cidadão, capaz de atuar de forma participativa, crítica e criativa, com mobilidade e flexibilidade, na vida profissional e social" (SENAI, 2009b, p. 11).

Finalmente, deve-se partir para o estabelecimento de uma prática pedagógica (como se ensina) adequada a estas necessidades, a qual, para tornar-se eficaz, com foco na educação profissional, alguns pressupostos devem ser atendidos (SENAI, 2009c):

- Interdisciplinaridade: uma abordagem integrada de diferentes áreas de conhecimento, permitindo um diálogo entre elas;

- Contextualização: trazer ao processo educacional, percepções, conhecimentos e experiências vividas pelos estudantes, a fim de dar um significado ao que é ensinado;

- Desenvolvimento de capacidades: estimular o desenvolvimento de capacidades que permeiam de maneira transversal as competências;

- Privilegiar o aprender a aprender, estimulando a descoberta de novas perspectivas, criativamente;

- Aproximar a formação ao mundo real, ao trabalho e às práticas sociais;

- Integrar teoria e prática;

- Avaliação da aprendizagem: sob as óticas de função reguladora, diagnóstica, formativa e promotora de melhoria contínua, superando a mera avaliação de conteúdos;

- Tornar presente o valor da afetividade, permitindo uma aprendizagem significativa ao colocar ao lado da seriedade e da atenção que o estudo exige o espaço da alegria, da convivência, da empatia e da solidariedade no ambiente escolar. 
Para tal, esta prática pedagógica pode ser estruturada fundamentalmente em situações de aprendizagem e cuja ênfase dos processos de ensino e aprendizagem devem recair sobre situações problema, projetos, pesquisa ou estudos de caso, aproximando o dia a dia escolar do mundo real. Este alinhamento possibilita uma maior adequação do perfil do egresso às necessidades do mundo do trabalho. (SENAI, 2009c).

Neste contexto, situação de aprendizagem é definida como:

\begin{abstract}
Atividade desafiadora que, planejada pedagogicamente, considera a interseção entre o difícil e o possível para o aluno num determinado momento. Deve ser contextualizada, ter valor sociocultural, evocar saberes e propor a solução de um "problema", que exija tomada de decisão, testagem de hipóteses e transferência de aprendizagens, ampliando no aluno a consciência de seus recursos cognitivos. (SENAI, 2009c, p. 29).
\end{abstract}

Por sua vez, a aplicação de ferramentas tecnológicas na educação profissional tem o propósito de suportar e apoiar o processo educacional, tornando-o ao mesmo tempo mais atrativo e mais efetivo.

\title{
2.3 A aplicação das Tecnologias da Informação e Comunicação (TIC) na educação profissional
}

A tecnologia, quando utilizada de forma adequada e inserida no processo educacional, potencializa seus resultados, auxiliando os estudantes a desenvolverem os mais diversos tipos de habilidade (STROMMEN e LINCOLN, 1992, tradução nossa). De acordo com o então Diretor do Setor de Comunicação e Informação da UNESCO, Abdul Waheed Khan:

\footnotetext{
Para viver, aprender e trabalhar bem em uma sociedade cada vez mais complexa, rica em informação e baseada em conhecimento, os alunos e professores devem usar a tecnologia de forma efetiva, pois em um ambiente educacional qualificado, a tecnologia pode permitir que os alunos se tornem: usuários qualificados das tecnologias da informação; pessoas que buscam, analisam e avaliam a informação; solucionadores de problemas e tomadores de decisões; usuários criativos e efetivos de ferramentas de produtividade; comunicadores, colaboradores, editores e produtores; cidadãos informados, responsáveis e que oferecem contribuições. (UNESCO, 2009, p. I, tradução nossa).
}

Vale ressaltar que, tão importante quanto qual tecnologia usar, é como o aprendizado pode ser aprimorado por meio de seu uso. Os docentes devem ter claro qual abordagem pedagógica se pretende, quais as necessidades dos estudantes bem como quais os objetivos de aprendizagem em questão. (STROMMEN e LINCOLN, 1992, tradução nossa). 
Chinien (2005, tradução nossa) reforça que o desenvolvimento de um planejamento estratégico é essencial para uma implementação bem sucedida das TIC como apoio nos processos de ensino e aprendizagem, passando pelo estabelecimento de uma visão (alinhada à visão da instituição), uma missão, uma estratégia para a implementação e uma análise da viabilidade financeira, além da definição de uma política de governança deste uso da tecnologia.

MacKinnon (2002, p. 57, tradução nossa) afirma que "os objetivos educacionais mudam de acordo com novas necessidades sociais e da mesma forma isto acontece com as estratégias para a integração da tecnologia nos processos de ensino e aprendizado".

Chris Chinien (2005, tradução nossa) apresenta uma série de potenciais usos das TIC em educação profissional:

- Ensino e aprendizagem

- Avaliar o ensino e a aprendizagem

- Avaliação e reconhecimento do aprendizagem prévia

- Pesquisa e comunicação

- Encaminhamento de graduados ao mercado de trabalho

- O desenvolvimento de programas

- Informações sobre o mercado de trabalho

- Educação e orientação sobre carreira

- Propósitos administrativos

- Aprendizes com necessidades especiais

- Estágios virtuais

- Desenvolvimento informal de habilidades

Dentre estas, ao focar-se principalmente no apoio aos processos de ensino e aprendizagem e de sua avaliação, em um escopo de educação profissional, em uma abordagem construtivista, adotando-se uma prática pedagógica baseada em situações de aprendizagem e em alinhamento às habilidades do século 21 , propõe-se uma plataforma tecnológica que apoie estes processos. 


\title{
3 PROPOSTA DE PLATAFORMA TECNOLÓGICA DE APOIO AOS PROCESSOS EDUCACIONAIS
}

A proposta aqui apresentada representa uma visão ampla de algumas soluções tecnológicas que se apresentam úteis, de maneira geral, a cursos de educação profissional que apresentem as características apresentadas ao final do item anterior, não sendo uma proposta completa ou mesmo aplicável a todas as instituições ou mesmo a todos os cursos.

Para viabilizar a utilização destas soluções tecnológicas, os atores envolvidos no processo educacional devem se valer de dispositivos de acesso como computadores (desktops ou notebooks) ou dispositivos móveis (como tablets ou smartphones) conectados à internet, possibilitando uma maior mobilidade, permitindo o acesso aos recursos a qualquer hora e a partir de qualquer lugar, dentro ou fora dos limites da escola.

A plataforma tecnológica proposta é composta de oito principais elementos:

a) Dispositivos de projeção e interação

Um dos recursos tecnológicos mais usuais para a apresentação de materiais a um grupo (por exemplo, uma turma em uma sala de aula) é o projetor multimídia, que é um dispositivo conectado a um computador que passa a reproduzir o conteúdo de sua tela em uma dimensão maior, visível a todo o grupo.

José Manuel Moran (2004) destaca que:

\begin{abstract}
Um projetor multimídia com acesso a Internet permite que os professores ealunos mostrem simulações virtuais, vídeos, jogos, materiais em CD, DVD, páginas WEB ao vivo. Serve como apoio ao professor, mas também para a visualização de trabalhos dos alunos, de pesquisas, de atividades realizadas no ambiente virtual de aprendizagem (um fórum previamente realizado, por exemplo). Podem ser mostrados jornais on-line, com notícias relacionadas com o assunto que está sendo tratado em classe. Os alunos podem contribuir com suas próprias pesquisas on-line. (MORAN, 2004, p. 4).
\end{abstract}

Já uma lousa interativa é também um dispositivo conectado a um computador que, além de exibir o conteúdo de sua tela (o que normalmente é feito por um projetor acoplado a este sistema), permite manipulá-lo diretamente pela projeção utilizando-se das mãos (quando em uma tela sensível ao toque) ou com algum dispositivo especial, normalmente na forma de uma caneta, como se o usuário estivesse utilizando um mouse, com o qual podem realizar anotações, marcações ou mesmo escrever sobre o que está projetado, além da possibilidade de gravar, imprimir e distribuir o material exposto.

Segundo Glover e Miller (2001, p. 258, tradução nossa), "uma lousa interativa é mais do que um computador, um projetor ou uma tela - sua soma é maior que suas partes", permitindo que docentes e estudantes utilizem materiais de alta qualidade como imagens, animações, vídeos, textos, simulações, diagramas, materiais online, de maneira a ficar visível a toda uma classe, sem o empecilho de estar "escondido" atrás de um computador. 
Porém, se for utilizado apenas como um projetor melhorado, seu potencial é desperdiçado e a mudança pedagógica possível por seu uso pode não acontecer (GLOVER e MILLER, 2001, tradução nossa). De fato, verifica-se um aumento da motivação dos estudantes quando lousas interativas são adotadas em sala de aula, porém ainda são necessários estudos mais aprofundados para confirmar se seu uso de fato melhora o aprendizado (HIGGINS, BEAUCHAMP e MILLER, 2007, tradução nossa).

b) Ambiente virtual de aprendizagem (AVA)

O ambiente virtual de aprendizagem é o sistema central de apoio aos processos de ensino e aprendizagem, integrando diversos recursos digitais. Dentre suas principais funcionalidades estão o controle de acesso dos usuários (docentes, estudantes, gestores, visitantes etc.) a conteúdos, a gestão dos cursos e turmas, de atividades, de avaliações, podendo ter integração com outros sistemas gerenciais da instituição como correio eletrônico, controle financeiro, gestão de pessoas, controle acadêmico, entre outros.

- Dentre as características desejáveis de um ambiente de aprendizagem estão:

- Possibilitar a expressão de diferentes modos de aprender;

- Flexibilizar o atendimento a demandas e a necessidades individuais de aprendizagem;

- Expressar, sempre que possível, a complexidade do mundo real empresarial e social;

- Possibilitar a integração funcional no sentido de que os diversos atores que interagem no processo formativo, em especial os docentes, possam se articular, discutir questões comuns, afinar entendimentos, o que fortalecerá a ação coletiva, quando necessária, e a gestão compartilhada. (SENAI, 2009c, p. 19)

Este ambiente pode também congregar os demais sistemas de apoio ao processo educacional, apresentados a seguir.

c) Banco de recursos didáticos

É um repositório, uma biblioteca de recursos didáticos digitais, no qual podem ser organizados materiais didáticos produzidos por docentes ou mesmo obtidos de fontes externas, além de possibilitar o armazenamento dos trabalhos dos estudantes.

Apesar de recursos digitais e informações em geral estarem amplamente disponíveis na internet, um banco de recursos próprio da instituição (ou mesmo de um grupo de instituições) tem como um de seus principais benefícios uma qualificação prévia do que é publicado, uma vez que apenas usuários autorizados podem inserir ou sugerir algum material no sistema, como, por exemplo, seus docentes, ficando estes materiais disponíveis apenas ao escopo que se deseja como, por exemplo, um grupo específico de docentes ou estudantes, todos os estudantes de uma unidade curricular, turma, curso ou instituição, ou mesmo pessoas externas à instituição como empregadores e familiares. 
Ao aliar este repositório a um sistema de recomendação, por meio do qual os usuários podem basear-se na qualificação que outros usuários (ou mesmo ferramentas inteligentes do próprio sistema) deram aos recursos publicados, em conjunto com uma ferramenta de busca avançada, que permita encontrar recursos, por exemplo, por autor, data, número de visualizações ou assunto, tem-se um grande ganho não somente no acesso a recursos mais adequados ou personalizados ao interesse do usuário, mas também servem como uma forma de avaliação da atualidade e pertinência de seu conteúdo, direcionando sua renovação e, eventualmente, até mesmo correções.

Também pode ser uma forma de identificar qual o perfil de determinado estudante em relação a suas preferências e estilos de aprendizado, ao se verificar qual o tipo de recurso didático este prefere: textos, imagens, vídeos, animações, simuladores, etc.

\title{
d) Portfólio digital
}

Outra possibilidade de utilização de um banco de recursos didáticos é a de utilizá-lo para organizar o portfólio do estudante.

\begin{abstract}
Portfólio é um instrumento que compreende a compilação de todos os trabalhos realizados pelos alunos, durante um curso, um módulo ou uma unidade curricular. Inclui entre outros elementos: registros de visitas, resumos de textos, projetos e relatórios de pesquisa, anotações de experiências etc. Inclui também ensaios auto-reflexivos, que permitem aos alunos a discussão de como a experiência mudou sua vida. (SENAI, 2009c, p.86)
\end{abstract}

Assim, além de servir como uma ferramenta de avaliação do desempenho do estudante por ele próprio ou por seus docentes, o portfólio também pode ser utilizado como um currículo vivo e dinâmico das atividades realizadas pelo estudante durante seu período escolar, podendo tornar-se mais efetivo do que um currículo tradicional, onde normalmente apenas relatam-se as atividades desenvolvidas. Neste caso, um possível empregador, por exemplo, pode realmente ter contato com a produção do estudante de uma forma mais concreta.

\section{e) Ferramentas de comunicação e colaboração}

A colaboração e a comunicação entre os públicos da escola devem estar presentes, apoiando os processos de ensino e aprendizagem, facilitando a interação entre estudantes, docentes, gestores, sociedade, família, mercado de trabalho, enfim, com qualquer um que tenha um acesso à internet e que possa contribuir para o processo educacional.

Dentre estas estão ferramentas como correio eletrônico (e-mail), listas de discussão, fóruns, redes sociais, ferramentas de bate papo (chat), sistemas de mensagem instantânea, entre outros, todos os quais podem estar integrados ao ambiente virtual de aprendizagem (TINIO, 2003, tradução nossa). 
Além destas, destacam-se sistemas baseados em vídeo como webconferência e videoconferência, os quais permitem a interação ponto a ponto ou multiponto, sendo a webconferênciautilizada basicamente por meio de computadores (ou dispositivos móveis com acesso a internet como tablets e smartphones), enquanto a videoconferência necessita de um sistema e equipamentos específicos.

Atividades como reuniões de trabalho envolvendo quaisquer dos atores do processo educacional, em especial docentes ou estudantes, apresentações de trabalho, orientação de atividades, esclarecimento de dúvidas são algumas das possibilidades ao se utilizar destes sistemas.

Além disso, é possível utilizar estas tecnologias para aproximar a escola das empresas, ao permitir que especialistas apresentem novidades ou informações técnicas de determinada área aos estudantes, sem a necessidade de se deslocar até o ambiente escolar. $\mathrm{O}$ caminho inverso também pode ser realizado, ao permitir que os estudantes apresentem o resultado de seus trabalhos a empresas.

f) Simulações

Simulações são representações computacionais de algum fenômeno do mundo real por meio de regras pré-definidas de operação, comportamento de objetos e interação entre objetos. (GREDLER, 2003, tradução nossa)

Há dois tipos de simulações: empíricas e simbólicas. A primeira permite a interação do estudante como um participante, agindo de acordo com os parâmetros e restrições, recebendo retorno e continuando a tomar decisões de acordo com a evolução das situações, usualmente com uma sensação de imersão, com imagens e movimentos, aproximando-se muito de um equipamento ou situação real. Normalmente é utilizada para reproduzir que tem custo ou risco elevado caso fosse realizada no mundo real como, por exemplo, um simulador de voo. Já as simbólicas diferenciam-se por fornecer uma experiência diferente ao estudante, na qual ele atua como um pesquisador, experimentador ou na resolução de problemas, cuja principal atividade é a de simular algum fenômeno ou experimento, como, por exemplo, o funcionamento de um circuito elétrico, onde o usuário pode alterar parâmetros a fim de verificar os resultados de sua atividade. (GREDLER, 2003, tradução nossa)

Um de seus principais benefícios está exatamente nesta possibilidade de se realizar determinados experimentos sem a necessidade de um equipamento real, podendo ser utilizado antes do acesso ao equipamento, como uma preparação do estudante para tal, ou mesmo substituindo-o, quando o equipamento real estiver indisponível ou inacessível, ou perante uma situação de alto custo ou perigosa. 
g) Jogos

Robert Hays (2005, p. 15, tradução nossa) define jogo como "uma atividade construída artificialmente, competitiva, com um objetivo específico, um conjunto de regras e condicionantes que é localizada em um contexto específico". Ao levarmos este conceito a um meio digital, refina-se a definição ao estabelecer que o sistema do jogo incorpore o componente tecnológico. (MCCLARTY et al., 2012, tradução nossa)

Seu uso é normalmente associado ao desenvolvimento de habilidades complexas de raciocínio e resolução de problemas, planejamento e aprendizado autônomo. (LEMKE, COUGHLIN e REIFSNEIDER, 2009, tradução nossa)

John Kirriemuir (2002, tradução nossa) aponta alguns benefícios do uso de jogos no processo educacional, desde que inseridos em um contexto relevante à atividade ou meta de aprendizado:

- No nível mais básico (e constantemente citado na mídia), os jogadores desenvolvem a coordenação de mão e visão;

- o desenvolvimento de habilidades estratégicas, por meio de jogos contemporâneos que são cada vez mais complexos e não lineares;

- (contrário ao estereótipo de que jogar é uma ação de isolamento social) o desenvolvimento de habilidades de trabalho em equipe, sociais, de comunicação e de compartilhamento de recursos, por meio de jogos multiusuários e jogos e simulações orientados a equipes;

- estímulo à curiosidade e encorajamento à experimentação em um ambiente "virtual" seguro. (KIRRIEMUIR, 2002, p.6)

h) Acesso remoto a laboratórios

Os laboratórios para atividades práticas são essenciais no processo de educação profissional. Porém, o acesso a estes ambientes muitas vezes é restrito, por conta de sua alta utilização, tornando-se um recurso raro e disputado por docentes e estudantes de diversas unidades curriculares ou cursos. Por outro lado, um laboratório destes pode acabar sendo subutilizado, pois é necessário apenas a algumas unidades curriculares ou atividades específicas.

Além dos benefícios educacionais, que consistem em permitir uma experimentação dos recursos tecnológicos disponíveis muito próxima ou idêntica à que se tem quando se acessa diretamente os equipamentos, seu uso pode trazer ganhos na otimização dos recursos da instituição de ensino, podendo, por exemplo, permitir acesso remoto aos laboratório em horários alternativos aos das aulas, proporcionando que mais estudantes e docentes os utilizem, ou, no caso de instituições multicampi, centralizar laboratórios em uma localidade, porém permitir que as demais também se beneficiem utilizando-os por meio de um acesso remoto. 
Podem fazer parte de sua arquitetura um software de gerenciamento de agendamentos, equipamentos configuráveis e programáveis com ensaios predefinidos, software supervisório para o monitoramento e a verificação dos resultados dos ensaios, câmeras de vídeo para a visualização remota da execução dos ensaios em tempo real, trabalhando de maneira integrada ao ambiente virtual de aprendizagem, de forma a permitir que os estudantes consultem informações e orientações necessárias ao uso dos equipamentos do laboratório remoto, realizem os ensaios e verifiquem seus resultados, além de possibilitar que o docente analise as informações sobre os resultados dos ensaios.

Esta proposta de plataforma tecnológica não é exaustiva nem estática, uma vez que a tecnologia adotada deve ser analisada e selecionada de acordo com as características específicas de cada caso, seja no escopo de uma instituição, curso, turma ou mesmo unidade curricular.

Com estes elementos em conjunto, porém, espera-se uma formação do estudante mais adequada às características do mundo atual, aproveitando-se ao máximo dos benefícios proporcionados pelo uso da tecnologia no processo educacional.

Vale ressaltar que a simples instalação destes ou quaisquer outros recursos tecnológicos no ambiente escolar, sem uma capacitação adequada dos atores envolvidos, principalmente dos docentes, pode ter o efeito contrário ao desejado, tornando-se um elemento complicador ao processo educacional.

\section{CONCLUSÃO}

As habilidades exigidas dos trabalhadores no mundo de hoje estão fortemente aliadas a conceitos como colaboração, criatividade, raciocínio crítico e comunicação, onde a necessidade por habilidades mecânicas, de repetição de tarefas, dá lugar à resolução de problemas.

Com isto, há uma necessidade de adequação do modelo educacional a este novo mundo e ao novo perfil do estudante, aproveitando-se ao máximo dos recursos digitais para tal.

O conjunto de elementos plataforma tecnológica proposta permite maior adequação do mundo educacional às demandas do mundo do trabalho, ao proporcionar um ambiente mais colaborativo, interativo, criativo, com maior mobilidade, resultando em uma educação profissional mais significativa e alinhada às necessidades do mundo do trabalho e ao perfil dos estudantes desta nova geração. 


\title{
TECHNOLOGICAL SUPPORT PLATFORM FOR PROFESSIONAL EDUCATION
}

\begin{abstract}
The world has been changing deeply and significantly, and is more diverse and interconnected. It's an era of connections, a networked society, provided mainly by the mass use of the information and communication technologies. It also transforms the working world, demanding a new profile of the worker, requiring fewer repetition tasks and more problems solving. This, combined to the fact that there is a new generation that was born into a digital world, requires changes in the educational universe, especially on professional education, both in pedagogical and technological scopes. This article proposes a technological platform to support the teaching and learning processes, focusing on professional education, and aligned to the needs of training a new professional, appropriate to the demands of current and future world. This proposal presents eight main elements: projection and interaction devices, learning management system (LMS), learning resources databank, digital portfolio, communication and collaboration tools, simulations, games and remote access to labs. Its usage, supported by an adequate pedagogical model, results in a professional education that is more significant and aligned to the need of the current and future working world.
\end{abstract}

Key-words: Professional Education. Information and Communication Technology. Educational Technology. 


\section{REFERÊNCIAS}

ANDERMAN, Eric. The teaching and learning of 21st century skills.In: NRC WORKSHOP ON ASSESSMENT OF 21ST CENTURY SKILLS, 2011, National Research Council, Irvine, Califórnia, EstadosUnidos: 2011. Disponível em <http://www7.nationalacademies.org/ bota/21st_Century_Workshop_Anderman_Paper.pdf>. Acesso em: 3 out. 2011.

ANDERSON, Jonathan. ICT transforming education: a regional guide. Tailândia: UNESCO, 2010. ISBN 978-92-9223-326-6. Disponível em: <http://unesdoc.unesco.org/ images/0018/001892/189216e.pdf >. Acesso em: 8 dez. 2011.

BLURTON, C., New Directions of ICT-Use in Education. [S.I.]: UNESCO. 1999. Disponível em <http://www.unesco.org/education/educprog/lwf/dl/edict.pdf >. Acesso em: 1 nov. 2012.

BRASIL. Presidência da República. Lei $n^{\circ}$ 9.394, de 20 de dezembro de 1996: estabelece as diretrizes e bases para a educação nacional. 1996. Disponível em <http://www. planalto.gov.br/ccivil_03/leis/L9394.htm>. Acessoem: 3 out. 2012.

CHINIEN, Chris. ICT application in technical and vocational educations and training. Moscou: UNESCO Institute for Information Technologies in Education., 2005. ISBN 5-902116-12-0. Disponível em: <http://iite.unesco.org/pics/publications/en/ files/3214643.pdf>. Acesso em: 4 out. 2012.

DEMO, Pedro. Olhar do educador e novas tecnologias. Boletim Técnico do Senac, v. 37, n. 2, p.15-26, maio/ago. 2011. Disponível em <http://www.senac.br/BTS/372/artigo2. pdf>. Acesso em: 8 out. 2012.

GLOVER, Derek; MILLER, David.Running with technology: the pedagogic impact of the large-scale introduction of interactive whiteboards in one secondary school. Journal of Information Technology for Teacher Education, vol. 10, n. 3, p. 257-278, 2001.Disponível em: <http://www.tandfonline.com/doi/pdf/10.1080/14759390100200115>. Acesso em: 6 out. 2012.

GREDLER, Margaret E. Games and simulations and their relationship to learning. Handbook of research on educational communications and technology, vol. 21, pp. 571-582, 2003.Disponível em:<http://www.coulthard.com/library/Files/gredler_2004_ gamesandsimsandrelationtolearning.pdf>. Acesso em: 6 out. 2012.

HAYS, Robert T. The effectiveness of instructional games: a literature reviewand discussion. Orlando, Estados Unidos: 2005. Disponível em <http://www.dtic.mil/cgi-bin/ GetTRDoc?AD=ADA441935\%26Location>. Acesso em: 6nov. 2012.

HIGGINS, Steve; BEAUCHAMP, Gary; MILLER, Dave. Reviewing the literature on interactive whiteboards. Learning, Media and Technology, v. 32, n. 3, p. 213-225, 2007.Disponível em: <http://dx.doi.org/10.1080/17439880701511040>. Acesso em: 4 nov. 2012. 
KIRRIEMUIR, John. The relevance of video games and gaming consoles to the Higher and Further Education learning experience.[S.I.: s.n.], 2002. Disponível em: <http:// tecnologiaedu.us.es/nweb/htm/pdf/301.pdf>. Acesso em: 4 nov. 2012.

LEMKE, Cheryl; COUGHLIN, Ed. ; REIFSNEIDER, Daren. Technology in schools: what the research says - a 2009 update. Culver City, Estados Unidos: CISCO, 2009. Disponível em: <http://www.cisco.com/web/strategy/docs/education/tech_in_schools_what_ research_says.pdf>. Acesso em: 27 set. 2012.

LEVY, Frank; MURNANE, Richard.J.The New Division of Labor: How Computers Are Creating the Next Job Market. New Jersey: Princeton University Press, 2004. ISBN 0-69111972-4.

LÉVY, Pierre. Cibercultura. 2. ed. São Paulo, SP: Ed. 34, 2000. 260 p. ISBN 8573261269.

LIPKIN, Nicole; PERRYMORE, April. A geração Y no trabalho: como lidar com a força de trabalho que influenciará definitivamente a cultura da sua empresa. Rio de Janeiro: Elsevier, 2010. 232 p.

MacKINNON, Soledad. Technology integration in the classroom: is there only one way to make it effective?. TechKnowLogia, v. 4, n.4, p. 57-60, out./dez. 2002. Disponível em: <http://www.techknowlogia.org/TKL_Articles/PDF/445.pdf>. Acesso em: 5 out. 2012.

MANTOAN, Maria Teresa Eglér. Ensinando a turma toda: as diferenças na escola. Pátio Revista pedagógica, Porto Alegre, Ano 5, n 20, p.18-28, 2002.

MCCLARTY, Katie Larsen, et al. A literature review of gaming in education: research report. [S.I]: Pearson, 2012. Disponível em <http://www.pearsonassessments.com/hai/ Images/tmrs/Lit_Review_of_Gaming_in_Education.pdf>. Acesso em: 1 nov. 2012.

MELO, Amanda Meinke, et al. Desafios para a Tecnologia da Informação e Comunicação em Espaço Educacional Inclusivo. In: CONGRESSO DA SOCIEDADE BRASILEIRA DE COMPUTAÇÃO, 25., 2005, São Leopoldo, RS. Anais... São Leopoldo, RS, UNISINOS, 2005.p.2540-2548. Disponível em: <styx.nied.unicamp.br:8080/todosnos/artigoscientificos/arq0002.pdf>. Acesso em: 22 set. 2012.

MORAN, José Manuel. Os novos espaços de atuação do educador com as tecnologias. In: ENDIPE - ENCONTRO NACIONAL DE DIDÁTICA E PRÁTICA DE ENSINO, 12., 2004, Curitiba. Anais... Curitiba: 2004. p.245-253. Disponível em: <http://www.eca.usp.br/ moran/espacos.htm>. Acesso em: 21 set. 2012

MULLER, Suzana Pinheiro Machado. O impacto das tecnologias de informação na geração do artigo científico: tópicos para estudo. Ci. Inf., Brasília, v. 23, n. 3, p. 309-317, set./dez. 1994. Disponível em: <http://capim.ibict.br/index.php/ciinf/article/view/1148/794>. Acesso em: 23 nov. 2011. 
PEREZ, Carlota. Technological revolution sand financial capital: the dynamics of bubble sand golden ages. Reino Unido, Edward Elgar, 2002. ISBN 1840649224.

PRENSKY, Mark. Digital natives, digital immigrants.MCB University Press, vol. 9, n. 5, out.2001. Disponível em: <http://www.marcprensky.com/writing/Prensky\%20-\%20 Digital\%20Natives,\%20Digital\%20Immigrants\%20-\%20Part1.pdf>. Acesso em: 15 set. 2012.

REICH, Robert B. O futuro do sucesso: o equilíbrio entre o trabalho e qualidade de vida. 1. ed. brasileira. Barueri: Manole, 2002. ISBN 85-204-1508-3.

ROTTA, Ivana Salvagni. Os desafios da organização do trabalho: o novo perfil dos trabalhadores e as principais tendências no século XXI. In: ENEGEP 2001. Disponível em: <http://www.abepro.org.br/biblioteca/enegep2001_tr15_0483.pdf>. Acesso em: 25 out. 2012.

SERVIÇO NACIONAL DE APRENDIZAGEM INDUSTRIAL. Departamento Nacional. Elaboração de desenho curricular. 3. ed. Brasília (DF): SENAI/DN, 2009a. v. 2, 64 p. ISBN 9788575193075.

Departamento Nacional. Elaboração de perfis profissionais por comitês técnicos setoriais. 3. ed. SENAI/DN, 2009b. 73 p. ISBN 9788575193044.

. Departamento Nacional. Norteador da prática pedagógica. 3. ed. Brasília (DF): SENAI/DN, 2009c. 107 p. ISBN 9788575193068.

SILVA, Elena. Measuring Skills for 21st-Century Learning. Phi DeltaKappan, vol. 90, no. 09, may 2009, pp. 630-634, 2009.

STROMMEN, Erik F., LINCOLN, Bruce.Constructivism, technology, and the future of classroom learning. Education and urban society, vol. 24, no. 4, pp. 466-476, ago. 1992. Disponível em: <http://www. playfulefforts.com/archives/papers/eus-1992.pdf>. Acesso em: 3 out. 2012.

TAPSCOTT, Don. Grown Up Digital: How the Net Generation is Changing Your World. 1. ed. McGraw-Hill, 2008. 384 p. ISBN 0071508635.

TINIO, Victoria L. ICT in education. Bangkok: UNDP-Asia Pacific Development Information Programme (APIP), 2003. Disponível em:<http://www.saigontre.com/FDFiles/ICT_in_ Education.pdf>. Acessoem: 15 out. 2012.

UNITED NATIONS EDUCATIONAL SCIENTIFIC AND CULTURAL ORGANIZATION. Padrões de competência em TIC para professores. [S.I.: s.n.], 2009.

.Revised recommendation concerning technical and vocational education.[S.I.: s.n.],2001. Disponível em: <http://unesdoc.unesco.org/images/0012/001246/124687e. pdf\#page=32>. Acesso em: 19 set. 2011. 


\section{SOBRE OS AUTORES}

Graduado em Ciências da Computação (UFSC, 1995), especialista em
Gerenciamento de Projetos (SENAI, 2011) e mestre em Engenharia de
Produção (UFSC, 2004). Atua desde 1995 em projetos na área de tecnologia
da informação e comunicação. Atuou como gestor e docente em cursos
técnicos, superiores e de pós-graduação no SENAI Florianópolis. Atualmente
é Especialista em Educação no SENAI/SC, atuando na gestão de projetos de
educação profissional e na aplicação de recursos tecnológicos à educação.

Técnico em Desenho Industrial, Publicitário, graduado pela Universidade
do Extremo Sul Catarinense e mestrando em Administração pela mesma
universidade. Especialista em Design de Produtos e Didática do Ensino Superior
pela Faculdade Barddal. Foi professor nos cursos superiores de Moda e Estilo,
Design Gráfico e nos cursos técnicos de Design, Confecção do Vestuário e
Marketing, Publicidade e Propaganda. Pelo SENAI, em 8 anos de envolvimento
com a Olimpíada do Conhecimento o o World SkillsCompetition, apresenta em
seu currículo 12 medalhas conquistadas como docente treinador nas áreas
de Design Gráfico e Web Design. Atualmente é Especialista em Educação no
núcleo de Educação do Departamento Regional do SENAI/SC coordenando a
Etapa Estadual da Olimpíada do Conhecimento.

Graduado em Sistemas de Informação (UFSC, 2006), especialista em Gestão de
Segurança da Informação (SENAI, 2009) e pós-graduando em Governança de
TI (UFLA). Atua desde 2002 em projetos na área de tecnologia da informação
e comunicação. Atuou como instrutor em cursos de qualificação no SENAI
Florianópolis e gestor de tecnologia da informação na Direção Regional do
SENAI/SC. Atualmente é Coordenador de Projetos no SENAI/SC, atuando na
gestão do projeto de implantação do Instituto SENAI de Inovação em Sistemas
$\begin{aligned} & \text { Paulo Alberto } \\ & \text { Embarcados. } \\ & \text { Violada }\end{aligned}$

